\title{
Assessing apical transportation in curved canals: comparison between cross-sections and micro-computed tomography
}

Laila Gonzales Freire ${ }^{(a)}$

Giulio Gavini ${ }^{(b)}$

Rodrigo Sanches Cunha ${ }^{(\mathrm{c})}$

Marcelo dos Santos ${ }^{(\mathrm{b})}$

\footnotetext{
(a) Department of Esthetic Dentistry, School of Dentistry, University of São Paulo, São Paulo, SP, Brazil.

(b) Department of Esthetic Dentistry, School of Dentistry, University of São Paulo, São Paulo, SP, Brazil.

${ }^{(c)}$ Department of Restorative Dentistry, School of Dentistry, University of Manitoba, Winnipeg, MB, Canada.
}

Abstract: The aim of this study was to compare two methods of assessing apical transportation in curved canals after rotary instrumentation, namely, cross-sections and micro-computed tomography $(\mu \mathrm{CT})$. Thirty mandibular molars were divided into two groups and prepared according to the requirements of each method. In G1 (cross-sections), teeth were embedded in resin blocks and sectioned at 2.0,3.5, and $5.0 \mathrm{~mm}$ from the anatomic apex. Pre- and postoperative sections were photographed and analyzed. In $\mathrm{G} 2(\mu \mathrm{CT})$, teeth were embedded in a rubber-base impression material and scanned before and after instrumentation. Mesiobuccal canals were instrumented with the Twisted File (TF) system (SybronEndo, Orange, USA), and mesiolingual canals, with the EndoSequence (ES) system (Brasseler, Savannah, USA). Images were reconstructed, and sections corresponding to distances $2.0,3.5$, and $5.0 \mathrm{~mm}$ from the anatomic apex were selected for comparison. Data were analyzed using Mann-Whitney's test at a 5\% significance level. The TF and ES instruments produced little deviation from the root canal center, with no statistical difference between them $(\mathrm{P}>0.05)$. The canal transportation results were significantly lower $(0.056 \mathrm{~mm})$ in $\mathrm{G} 2$ than in G1 $(0.089 \mathrm{~mm})(\mathrm{p}=0.0012)$. The $\mu \mathrm{CT}$ method was superior to the cross-section method, especially in view of its ability to preserve specimens and provide results that are more closely related to clinical situations.

Descriptors: Endodontics; Root Canal Preparation; X-Ray Microtomography.

\section{Introduction}

Canal transportation is a frequent complication in the preparation of curved canals. When excessive dentin is removed in a single direction, some areas are left unprepared, favoring the presence of remaining necrotic tissue and compromising the apical seal after root canal filling. ${ }^{1}$

The introduction of instruments fabricated from nickel-titanium (Ni-Ti) has significantly improved the quality of root canal shaping, in great part because of their increased flexibility as compared with their stainless steel counterparts. ${ }^{2}$ Moreover, in the last few years, important modifications to rotary instruments have been proposed to increase their reliability and effectiveness. ${ }^{3,4}$

In addition to the advances made in rotary instrumentation, different methodologies have been proposed and used to assess the effects of endodontic instruments on canal transportation and on root canal anatomy. ${ }^{5-9}$ Physical crosssectioning is one of the experimental models currently available to evaluate changes in root canal anatomy before and after instrumentation. ${ }^{10}$ However,
Received for publication on Jan 17, 2012 Accepted for publication on Apr 03, 2012
Corresponding author:

Laila Gonzales Freire

E-mail: lailafreire@gmail.com 
sectioning invariably causes loss of dental hard tissue and the creation of ledges between sections. ${ }^{11}$ Moreover, the two-dimensional projections of three-dimensional structures provided by this method do not adequately represent the real object, reducing the accuracy of the analyses performed in quantitative studies. ${ }^{12}$

The search for more reliable and less invasive methods to assess apical transportation has led to the widespread use of micro-computed tomography $(\mu \mathrm{CT})$ in endodontic research. $\mu \mathrm{CT}$ allows researchers to evaluate both external and internal tooth morphology, and is an excellent and reproducible tool for examining root canal anatomy before and after preparation in a nondestructive manner. ${ }^{13,14}$ However, very few studies have compared $\mu \mathrm{CT}$ with other methodologies used to assess apical transportation.

The aim of this study was thus to compare the results obtained with $\mu \mathrm{CT}$ and cross-sections in determining apical transportation after instrumentation of curved canals with Ni-Ti rotary instruments.

\section{Methodology}

This study was approved by the Research Ethics Committee, School of Dentistry, University of São Paulo (USP) (protocol n. 161/2008). Thirty lower molars with intact pulp chambers, fully formed roots, two mesial canals with independent foramina, curvatures ranging from 25 to 35 degrees ${ }^{15}$ and a radius below $10 \mathrm{~mm}^{16}$ were selected from the human tooth bank at USP.

Tooth size was standardized at $18 \mathrm{~mm}$ by sectioning occlusal surfaces with a diamond disc (Buehler, Lake Bluff, USA). Following surgical access, the apical patency of mesial canals was checked using a $\# 10 \mathrm{~K}$ file (Dentsply/Maillefer, Ballaigues, Switzerland), by observing the canal until the tip of the file became visible at the apical foramen, aided by an operating microscope (Alliance, São Paulo, Brazil) at $8 \times$ magnification. Working length was established at $1.0 \mathrm{~mm}$ short of the distance measured with the $\mathrm{K}$ file.

The 30 specimens (60 root canals) were divided into two groups of 15 each, according to the method employed for assessing apical transportation:

- G1, cross-sections;

- G2, micro-computed tomography.

\section{G1: cross-sections}

The Bramante technique ${ }^{10}$ modified by SkeltonMacedo et al. ${ }^{17}$ was used to embed 15 mandibular molars in resin blocks, allowing visualization of the entire circumference of the root canal in cross-sections.

The distal root of the teeth was removed with a diamond disc. Pulp chambers were filled with cotton pellets (SSPlus, São Paulo, Brazil) and sealed with wax (Wilson Polidental, São Paulo, Brazil) to close the access cavities. A thin layer of black nail polish (Colorama, São Paulo, Brazil) was applied on the mesial roots of all specimens both to prevent resin leakage through the apical foramen and to improve contrast during specimen visualization.

Teeth were fixed onto glass plates (Jon, São Paulo, Brazil) by their occlusal surface using layers of wax. A metallic guide (Bateprego, São Paulo, Brazil), previously protected by wax, was placed on the proximal surface of each tooth. Specimens were placed inside 3-cm-long 3/4" PVC tubes (Tigre, Rio Claro, Brazil), previously lubricated with petroleum jelly (MSM Química, Diadema, Brazil). Tubes were then filled with fluid polyester resin (Resinfiber, São Paulo, Brazil). After 24 hours, the resin blocks containing the teeth were detached, and the metallic guides, removed.

Each specimen was sectioned at 2.0,3.5, and $5.0 \mathrm{~mm}$ from the anatomic apex, perpendicular to the long axis of roots, using a 0.3 -mm-thick diamond saw blade and an Isomet low-speed saw (Isomet 2000, Buehler, Lake Bluff, USA). All sections were photographed using a digital camera (Canon SD-630, São Paulo, Brazil) coupled to a stereomicroscope (Olympus, São Paulo, Brazil). Images were captured under $13.4 \times$ magnification using QCapture software (IBM Corporation, New York, USA).

\section{G2: micro-computed tomography}

The other 15 teeth were embedded in high-precision rubber-base impression material (Vigodent, Rio de Janeiro, Brazil), with the access cavities facing downwards, and mounted on a holder with an internal $15-\mathrm{mm}$ diameter. ${ }^{18}$ Negative replicas of the coronal structure were prepared to allow precise repositioning of the tooth on the holder, thus ensuring uniform acquisition of preand postoperative $\mu \mathrm{CT}$ scans.

Specimens were scanned with an X-ray micro-to- 
mography scanner (1172 SkyScan, Aartselaar, Belgium) at a voltage of $89 \mathrm{kV}$ and a current of $112 \mu \mathrm{A}$, with a 0.5 $\mathrm{mm}$ aluminum filter. X-rays were obtained at a resolution of $11.84 \mu \mathrm{m}$, and at multiple angles along a 180-degree rotation, at every 0.4 degrees. Each specimen was scanned for a total of 45 minutes.

Following preparation, each specimen was repositioned on the holder, and postoperative scans were obtained using the same parameters described above.

\section{Root canal instrumentation}

After manual instrumentation to a working length up to file \#15, mesiobuccal canals were instrumented with the Twisted File (TF) system (SybronEndo, Orange, USA), and mesiolingual canals, with the EndoSequence (ES) system (Brasseler, Savannah, USA). Cervical interferences were eliminated using Gates-Glidden burs \#2 (Dentsply/Maillefer, Ballaigues, Switzerland). Instruments were used according to a predetermined size/taper sequence (30/0.06, 25/0.06, and 25/0.04), coupled to an electric motor (X-Smart, Dentsply/Maillefer, Ballaigues, Switzerland). The speed was kept constant at $500 \mathrm{rpm}$, with no torque control.

In both groups, a single operator prepared all root canals. Instruments were used five times and then discarded. At each instrument change, root canals were irrigated with $3 \mathrm{~mL}$ of $1 \%$ sodium hypochlorite (Formula e Ação, São Paulo, Brazil). Final irrigation was performed with $5 \mathrm{~mL}$ of $17 \%$ ethylenediaminetetraacetic acid (EDTA) (Formula e Ação, São Paulo, Brazil), followed by $5 \mathrm{~mL}$ of $1 \%$ sodium hypochlorite.

Pre- and postoperative measurements

Pre- and postoperative distances were measured using ImageJ software (National Institutes of Health, Bethesda, USA) in G1, and CTan software (SkyScan, Aartselaar, Belgium), in G2. Distances between the edges of uninstrumented canals and the root edges were measured in the mesial and distal directions.

\section{Canal transportation assessment}

Canal transportation was calculated in millimeters using the formula [(X1-X2) - (Y1-Y2)], as described by Gambill et al. ${ }^{19}$

Apical transportation results obtained with the two methods were subjected to preliminary tests to verify the normality of the distribution. Since the tested sample presented a non-normal distribution, the Mann-Whitney non-parametric test was used, at a 5\% significance level, using BioEstat 5.0 software.

\section{Results}

To confirm the standardization of the sample regarding the angle and radius of the curvature of the canals, the experimental groups were submitted to statistical analysis (t-test; $\mathrm{P}>0.05$ ) (Table 1).

Table 2 shows the apical transportation results obtained for G1 and G2, comparing TF and ES instruments. Both systems presented little deviation from the center, with no statistical differences between them $(\mathrm{P}>0.05)$.

When considering only the methods, regardless of the instrument used, apical transportation was significantly lower in G2 as compared with G1 at 2.0 $(\mathrm{p}=0.0309)$ and $5.0 \mathrm{~mm}(\mathrm{p}=0.0130)$, and also considering the overall results for the three sections $(p=0.0012)$ (Table 3).

\section{Discussion}

Different methodologies have been used to evaluate root canal instrumentation as well as its consequences and complications. ${ }^{5-10}$ The limitations of each of these methods have been extensively discussed, ${ }^{11,20-23}$ encouraging continuing research into technologies that allow both quantitative and qualitative three-dimensional assessments of the root canal. To this end, the present study compared the $\mu \mathrm{CT}$ and the cross-sectioning methods used to quantify apical transportation after rotary instrumentation of curved canals at $2.0,3.5$, and $5.0 \mathrm{~mm}$ from the apex.

Sample homogeneity was ensured by selecting specimens with similar root structures. All selected molars had two distinct mesial canals to minimize potential

Table 1 - Angle of curvature (degree) and radius of curvature $(\mathrm{mm})$ in each Group (mean $\pm \mathrm{SD})$.

\begin{tabular}{c|c|c}
\hline Group & Curvature angle & Curvature radius \\
\hline $\mathrm{G} 1(\mathrm{n}=30)$ & $28.85 \pm 3.43$ & $6.80 \pm 1.69$ \\
\hline $\mathrm{G} 2(\mathrm{n}=30)$ & $29.26 \pm 4.13$ & $6.54 \pm 1.18$ \\
\hline P value & $0.8860^{*}$ & $0.6105^{*}$ \\
\hline
\end{tabular}

$\mathrm{SD}=$ standard deviation; $*$ not significantly different $(\mathrm{t}$-test $)$. 
Table 2 - Apical transportation values obtained for $\mathrm{G} 1$ and $\mathrm{G} 2$ (mean $\pm \mathrm{SD}$ ), comparing instruments TF and ES.

\begin{tabular}{|c|c|c|c|c|c|}
\hline \multirow{2}{*}{ Group } & \multirow{2}{*}{ Rotary } & \multicolumn{3}{|c|}{ Distance from the anatomical apex } & \multirow{2}{*}{ Total } \\
\hline & & $2.0 \mathrm{~mm}$ & $3.5 \mathrm{~mm}$ & $5.0 \mathrm{~mm}$ & \\
\hline \multirow{3}{*}{ G1 } & $\mathrm{TF}$ & $0.075 \pm 0.06$ & $0.094 \pm 0.07$ & $0.130 \pm 0.08$ & $0.099 \pm 0.04$ \\
\hline & ES & $0.079 \pm 0.06$ & $0.071 \pm 0.07$ & $0.087 \pm 0.07$ & $0.079 \pm 0.04$ \\
\hline & $P$ value & $0.8357^{*}$ & $0.3725^{*}$ & $0.1409 *$ & $0.2037 *$ \\
\hline \multirow{3}{*}{$\mathrm{G} 2$} & $\mathrm{TF}$ & $0.060 \pm 0.05$ & $0.041 \pm 0.03$ & $0.070 \pm 0.03$ & $0.057 \pm 0.03$ \\
\hline & ES & $0.035 \pm 0.03$ & $0.075 \pm 0.05$ & $0.051 \pm 0.04$ & $0.055 \pm 0.03$ \\
\hline & Pvalue & $0.2058^{*}$ & $0.9339 *$ & $0.4807 *$ & $0.2502 *$ \\
\hline
\end{tabular}

$\mathrm{TF}=$ Twisted File; $\mathrm{ES}=$ EndoSequence; $\mathrm{SD}$ = standard deviation; * not significantly different (Mann Whitney's test).

Table 3 - Apical transportation values obtained for G1 and G2, regardless of instrument used $($ mean $\pm \mathrm{SD})$.

\begin{tabular}{c|c|c|c|c}
\hline \multirow{2}{*}{ Group } & \multicolumn{3}{|c|}{ Distance from the anatomical apex } & \multirow{2}{*}{ Total } \\
\cline { 2 - 5 } & $2.0 \mathrm{~mm}$ & $3.5 \mathrm{~mm}$ & $5.0 \mathrm{~mm}$ & \\
\hline $\mathrm{G} 1$ & $0.077 \pm 0.06$ & $0.082 \pm 0.07$ & $0.108 \pm 0.07$ & $0.089 \pm 0.04$ \\
\hline $\mathrm{G} 2$ & $0.047 \pm 0.04$ & $0.060 \pm 0.04$ & $0.060 \pm 0.05$ & $0.056 \pm 0.03$ \\
\hline$P$ value & $0.0309^{*}$ & 0.2488 & $0.0130^{*}$ & $0.0012^{*}$ \\
\hline
\end{tabular}

$\mathrm{SD}=$ standard deviation; * Significantly different (Mann Whitney's test).

root canal variations of different teeth. Moreover, working length was standardized at $18 \mathrm{~mm}$, and the specimens were randomly divided into two groups of 15 , according to the angle values and curvature radii.

In G1 (cross-sections), teeth were embedded in resin blocks, which allowed the whole circumference of the root canal to be visualized. The main advantages of this widely-used method are the possibility to compare the root canal structure before and after instrumentation, and the fact that the analyzes are conducted in the real image of the root canal. ${ }^{10,11,20,21,24}$ However, disadvantages have also been described, e.g., assessment restricted to limited portions of the root canal, insofar as this is a two-dimensional technique, and material may be lost from serial tooth sectioning. Moreover, it is an invasive method, with irreversible changes to specimens.

The advent of computed tomography has made it possible to visualize the root canal system in three dimensions without destroying the sample. ${ }^{6,19,23}$ More recent technological advances have led to the development of micro-tomography systems, with improved image resolution and reduced scanning time. Peters et al. ${ }^{25}$ have stated that $\mu \mathrm{CT}$ resolutions are acceptable for the study of root canal anatomy, since anatomic changes along the long axis occur gradually. Rhodes et al. ${ }^{13}$ and Moore et al. ${ }^{8}$ also recommended $\mu \mathrm{CT}$ as an excellent al- ternative method for assessing the apical third of root canals.

Studies using tomographic assessments have shown correlations with cross-section assessments, attesting that both methods faithfully reproduce root canal dimensions. ${ }^{13,26}$ Moreover, Rhodes et $a l .{ }^{13}$ have compared $\mu \mathrm{CT}$ images of molars with photographs of crosssections at 2.0, 3.0, 4.5, 6.0, and $7.5 \mathrm{~mm}$ from the apex and have found a highly significant correlation between both methods. Balto et al. ${ }^{26}$ reported comparable results for $\mu \mathrm{CT}$ and histological sectioning in the analysis of induced periapical lesions in mice. Finally, Ounsi et al. ${ }^{12}$ compared photographic and $\mu \mathrm{CT}$ measurements in assessing the shaping capacity of Ni-Ti rotary instruments and found $\mu \mathrm{CT}$ to be more effective in discriminating changes in root canal anatomy as compared with photographic measurements.

In our study, $\mu \mathrm{CT}$ yielded significantly lower canal transportation values, as compared with G1. This difference may be explained by the loss of material associated with the physical sectioning performed in G1 (average loss of $0.30 \mathrm{~mm}$, which corresponds to the thickness of the diamond blade used). Sectioning creates artificial ledges during specimen reassembly and repositioning, clearly rendering apical instrumentation more difficult, because the instruments may fail to reach the working 
length on the first attempt. Other authors have also described this loss of root structure as leading to slight discrepancies between sections. ${ }^{11,20,21}$ Nonetheless, although the cross-section method obtains faithful measurements based on the real image of the specimen, sectioning of the roots does not allow simulation of clinical conditions during root canal preparation.

On the other hand, the $\mu \mathrm{CT}$ method has several advantages. First and foremost, it is a non-invasive tool that can simulate clinical situations more accurately. It provides detailed information on the internal anatomy of the tooth ${ }^{14}$ and is also considered an important educational resource for pre-clinical training in endodontics. ${ }^{8}$ Finally, $\mu \mathrm{CT}$ data can be stored and worked three-dimensionally at a later time for comparative or qualitative assessment purposes. ${ }^{27}$

The effect of the different instrument manufacturing methods - ground (ES) versus twisted (TF) —on the degree and direction of root canal transportation has been previously described. ${ }^{18} \mathrm{TF}$ and ES showed similar behavior, with no significant differences, considering the overall results of the cross-sections, ranging from 1 to $7 \mathrm{~mm}$ from the apex. In the present study, the apical transportation results also indicated that both TF and ES rotary systems prepared the mesial canals of mandibular molars with little deviation from the center, with no statistical difference.

Our findings are in accordance with those of several studies that have shown the ability of rotary $\mathrm{Ni}-\mathrm{Ti}$ instruments to stay centered in the canal, keeping the risk of canal transportation at minimum levels. ${ }^{8,21-23}$ Notwithstanding, literature data are quite varied, probably as a result of differences in sample characteristics, types of instrument tested, methodological procedures, and the evaluation method used. ${ }^{6,7}$

In sum, conducting studies such as the present one is warranted because different methods may have a direct impact on the results obtained. In this sense, we strongly believe that our findings add to the existing body of knowledge by reporting comparative data obtained with two methods ( $\mu \mathrm{CT}$ and cross-sections) used for assessing apical transportation in curved canals.

\section{Conclusion}

In this study, the TF and ES systems showed simi- lar behavior regarding apical transportation of curved canals, with minimal transportation. Both the crosssectioning and $\mu \mathrm{CT}$ methods seemed to reproduce root canal dimensions faithfully. Nevertheless, we believe $\mu \mathrm{CT}$ to be superior, especially in view of its ability to preserve specimens and provide results that are more closely related to clinical situations. We therefore recommend that $\mu \mathrm{CT}$ be preferred for assessing apical transportation in future experimental studies.

\section{Acknowledgments}

The authors are grateful to the São Paulo State Research Foundation (FAPESP) for the financial support provided (grant n. 2008/58312-0).

\section{References}

1. Wu MK, Fan B, Wesselink P. Leakage along apical root fillings in curved root canals Part I: Effects of apical transportation on seal of root. J Endod. 2000 Apr;26(4):210-6.

2. Walia $\mathrm{H}$, Brantley WA, Gerstein H. An initial investigation of the bending and torsional properties of nitinol root canal files. J Endod. 1988 Jul;14(7):346-51.

3. Gambarini G, Gerosa R, De Luca M, Garala M, Testarelli L. Mechanical properties of a new and improved nickel-titanium alloy for endodontic use: an evaluation of file flexibility. Oral Surg Oral Med Oral Pathol Oral Radiol Endod. 2008 Jun;105(6):798-800

4. Peters OA. Current challenges and concepts in the preparation of root canal systems: a review. J Endod. 2004 Aug;30(8):559-67.

5. Aydin C, Inan U, Yasar S, Bulucu B, Tunca YM. Comparison of shaping ability of RaCe and Hero Shaper instruments in simulated curved canals. Oral Surg Oral Med Oral Pathol Oral Radiol Endod. 2008 Mar;105(3):e92-7.

6. Gergi R, Rjeily JA, Sader J, Naaman A. Comparison of canal transportation and centering ability of twisted files, Pathfile-ProTaper system, and stainless steel hand K-files by using computed tomography. J Endod. 2010 May;36(5):904-7.

7. Karabucak B, Gatan AJ, Hsiao C, Iqbal MK. A comparison of apical transportation and length control between EndoSequence and Guidance rotary instruments. J Endod. 2010 Jan;36(1):123-5.

8. Moore J, Fitz-Walter P, Parashos P. A micro-computed tomographic evaluation of apical root canal preparation using three instrumentation techniques. Int Endod J. 2009 Dec;42(12):1057-64.

9. Interliche R, Marchesan MA, Silva SRC, Pécora JD, Silva-Sousa YDC, Sousa-Neto MD. Influence of Hero Apical instruments on cleaning ovoid-shaped root canals. Braz Oral Res. 2011 JulAug;25(4):314-8.

10. Bramante CM, Berbert A, Borges RP. A methodology for evaluation of root canal instrumentation. J Endod. 1987 May;13(5):243-5.

11. Imura N, Kato AS, Novo NF, Hata G, Uemura M, Toda T. A comparison of mesial molar root canal preparations using two engine- 
driven instruments and the balanced-force technique. J Endod. 2001 Oct;27(10):627-31.

12. Ounsi HF, Franciosi G, Paragliola R, Huzaimi KA, Salameh Z, Tay FR, et al. Comparison of two techniques for assessing the shaping efficacy of repeatedly used nickel-titanium rotary instruments. J Endod. 2011 Jun;37(6):847-50.

13. Rhodes JS, Pitt Ford TR, Lynch JA, Liepins PJ, Curtis RV. Microcomputed tomography: a new tool for experimental endodontology. Int Endod J. 1999 May;32(5):165-70.

14. Endal U, Shen Y, Knut A, Gao Y, Haapasalo M. A high-resolution computed tomography study of changes in root canal isthmus area by instrumentation and root filling. J Endod. 2011 Feb;37(2):223-7.

15. Schneider SW. A comparison of canal preparations in straight and curved root canals. Oral Surg Oral Med Oral Pathol. 1971 Aug;2(8):273-5.

16. Pruett JP, Clement DJ, Carnes DL Jr. Cyclic fatigue testing of nickel-titanium endodontic instruments. J Endod. 1997 Feb;23(2):77-85.

17. Skelton-Macedo MC, Cardoso RJA, Bombana AC. Sistema de corte transversal simplificado para estudo da morfologia do canal radicular e técnicas de preparo. Endod Clin Pract Educ Res. 1999 May;1(2) [citado 10 mar 2012]. Disponível em: http://ecler.bvs.br/ scielo.php.

18. Freire LG, Gavini G, Branco-Barletta F, Sanches-Cunha R, dos Santos M. Microscopic computerized tomographic evaluation of root canal transportation prepared with twisted or ground nickeltitanium rotary instruments. Oral Surg Oral Med Oral Pathol Oral Radiol Endod. 2011 Dec;112(6):e143-8.

19. Gambill JM, Alder M, Del Rio C. Comparison of nickel-titanium and stainless steel hand-file instrumentation using computed tomography. J Endod. 1996 Jul;22(7):369-75.

20. Nordmeyer S, Schnell V, Hülsmann M. Comparison of root canal preparation using Flex Master Ni-Ti and Endo-Eze AET stainless steel instruments. Oral Surg Oral Med Oral Pathol Oral Radiol Endod. 2011 Feb;111(2):251-9.

21. Rödig T, Hülsmann M, Kahlmeier C. Comparison of root canal preparation with two rotary NiTi instruments: ProFile .04 and GT Rotary. Int Endod J. 2007 Jul;40(7):553-62.

22. Özer SY. Comparison of root canal transportation induced by three rotary systems with noncutting tips using computed tomography. Oral Surg Oral Med Oral Pathol Oral Radiol Endod. 2011 Feb;111(2):244-50.

23. Pasternak-Júnior B, Sousa-Neto MD, Silva RG. Canal transportation and centring ability of RaCe rotary instruments. Int Endod J. 2009 Jun;42(6):499-506.

24. Aguiar CM, Mendes DA, Câmara AC, Figueiredo JAP. Assessment of canal walls after biomechanical preparation of root canals instrumented with ProTaper Universal rotary system. J Appl Oral Sci. 2009 Nov-Dec;17(6):590-5.

25. Peters OA, Schönenberger K, Laib A. Effects of four Ni-Ti preparation techniques on root canal geometry assessed by micro computed tomography. Int Endod J. 2001 Apr;34(4):221-30.
26. Balto K, Müller R, Carrington DC, Dobeck J, Stashenko P. Quantification of periradicular bone destruction in mice by microcomputed tomography. J Dent Res. 2000 Jan;79(1):35-40.

27. Paqué F, Ganahl D, Peters OA. Effects of root canal preparation on apical geometry assessed by micro-computed tomography. J Endod. 2009 Jul;35(7):1056-9. 